\title{
O psicanalista e a saúde coletiva ${ }^{1}$
}

\author{
Rosana Onocko Campos ${ }^{2}$ \\ "Mantener la mente abierta y, junto con la mente abierta, los principios \\ claros" \\ Silvia Bleichmar (2008)
}

A saúde coletiva nasce no Brasil com a entrada das ciências sociais no campo da saúde pública. A tese de Arouca "O dilema preventivista” (1975) foi pioneira ao aproximar as teorias de Foucault do campo de uma saúde pública higienista, vigilante, vertical, que sempre sabia quando e o quê prescrever. Em uma definição ampla, poderíamos dizer que a saúde coletiva se ocupa da saúde das populações e grupos sociais, estudando a distribuição de agravos e doenças, as estratégias para extensão da cobertura e da qualidade da assistência à saúde, e buscando desenvolver medidas para a prevenção e promoção da saúde. Disciplinarmente falando, nunca nos vimos livres dessa tensão constitutiva do campo: entre a prescrição tecnocrata e a omissão pós-moderna, donde poderíamos situar nossas contribuições?

O advento do Sistema Único de Saúde (SUS) - e sua extensão capilar a quase todas as comunidades no Brasil - permitiu que demandas variadas fossem encaminhadas ao setor saúde (simplesmente porque - às vezes - não há outra instituição representante do Estado). Assim, o sofrimento da pobreza, da violência, do racismo e do machismo comparecem em quantidade aos serviços públicos de saúde sem que possamos negligenciá-los. Ao mesmo tempo, os serviços encontram-se sobrecarregados, faltos de recursos materiais e com pessoal

\footnotetext{
${ }^{1}$ Este trabalho foi apresentado na mesa "O psicanalista e a saúde coletiva " com Silvia Maia Bracco no eixo "Psicanálise e suas clinicas" no I Simpósio Bienal "O mesmo, o outro: Psicanálise em movimento" da Sociedade Brasileira de Psicanálise de São Paulo.

${ }^{2}$ Médica, psicanalista, supervisora clínico-institucional, coordenadora da residência multiprofissional em Saúde Coletiva e Saúde Mental, professora do Departamento de Saúde Coletiva da faculdade de Ciências Médicas da Unicamp.
} 
insuficiente para as demandas colocadas. Parte dessa "insuficiência" é de quantidade de pessoas trabalhando, mas outra tem a ver com trabalhadores da saúde totalmente desguarnecidos de um repertório teórico conceitual.

É nesse ponto que gostaria de inserir a discussão sobre as diversas clínicas e o possível papel do psicanalista. Não defendendo que todos os trabalhadores de saúde mental do SUS se tornem psicanalistas, mas propondo que algumas valises teóricas da psicanálise possam inspirar nossas políticas públicas (Onocko-Campos et al, 2008). Para isso me valerei dalguns eixos temáticos para reflexionar sobre como o referencial teórico pode fazer diferença na organização e fundamentação de nossas práticas.

\section{- O feminino}

Como poderíamos, a partir de Freud, pensar a resistência ao feminino hoje (que persiste, a pesar dos vários feminismos)? Ao mesmo tempo que vemos o machismo limitar a vida de muitas mulheres, podemos mapear, também, uma rejeição maciça do feminino.

O cliché do feminino como doado, abnegado, sofrido é absolutamente funcional ao machismo vigente. A contra cara disso, mulheres competindo entre si e correndo contra o tempo para ascender no trabalho e na vida também não implica em uma aceitação do feminino. Pelo contrário, constitui uma colonização do capitalismo falocêntrico. Pretender que a igualdade de oportunidades chegará por meio de reivindicações menores é absurdamente simplista e funcional à ordem excludente prevalente. Como uma mulher pode ser trabalhadora e mãe na periferia quando as escolas funcionam $3 \mathrm{~h}$ por dia? Como contribuir para que essas questões (políticas, sociais) não velem o verdadeiro sofrimento dessas mulheres, que permanece quase sempre à margem? Como psicanalistas podemos ajudar os trabalhadores de saúde a estarem advertidos - como dizia Oury - para a existência do sintoma e do inconsciente. A não levarem a queixa ao pé da letra e - ao mesmo tempo - a legitimar um sofrimento que ali comparece, atestando sua verdade. 
Inútil patologizar nas comunidades o medo, ou o descontentamento. Pesquisas mostram (Soares JSF, Lopes MJM, 2018) que quando as mulheres demandam assistência por casos de violência doméstica, há uma tendência das equipes de saúde a prescrevê-las. Na mesma pesquisa, as mulheres declaram ter negado ser vítimas de violência por medo e/ou vergonha de ser julgadas pela equipe por, por exemplo, sustentar a relação com o agressor.

Em muitos locais, ter medo é sinal de princípio de realidade, aumenta as chances de sobrevivência. Bleichmar (2008) dizia que “a paz é o direito aos medos privados”, pelo contrário, vivemos tempos de medos coletivos. Deveríamos ajudar a transformar o descontentamento difuso em um vetor de ações políticas concretas. Deixo aqui um desafio ético-político para que nós, psicanalistas, não nos escondamos por trás da teoria ou do excesso de demanda persistindo na omissão.

Há em muitos centros de saúde grupos de mães, a maioria destinados a um certo “aconselhamento". Não que eles não ajudem. Mas, há poucos locais para se falar das agruras de ser mãe nessa conjuntura inóspita ${ }^{3}$. Menos ainda há grupos de mulheres, nos quais poder falar do inédito de ser mulher nesse tempo histórico e nesse local socio-geográfico. Penso que como psicanalistas temos a responsabilidade de alertar à equipe sobre a não linearidade do desejo, de ajudá-la a policiar o tratamento moral e a aceitar a própria frustração. E também de estimular a criação de dispositivos de fala e compartilhamento. Espaços que deem contenção e permitam restituir o valor da palavra e voltar a acreditar em legalidades aplicáveis.

\section{- Crianças, famílias, novos enlaces}

O Brasil negligencia a sua infância. Em que outro país o assassinato de uma criança pelo poder policial enquanto estava indo à escola teria passado sem passeatas, mobilizações e/ou demissões? Estamos anestesiados, alienados. As escolas, majoritariamente, trabalham na contramão do esperado: patologizam, estigmatizam e segregam milhares de crianças que reclamam da vida por meio de transgressões menores, hiperatividade, desatenção. Diagnosticam lhes falta de suporte familiar. Isso se traduz no setor saúde como demanda por medicação para esses pequenos seres humanos sofredores.

\footnotetext{
${ }^{3}$ Em um grupo de hipertensas que realizávamos todas as mulheres participantes tinham um filho preso ou que morrera assassinado, como falar ali somente da ingesta de sal?
} 
Há uma desistência das crianças pelas escolas. Como se a instituição escolar existisse para confirmar que a família não presta, em um claro movimento de estigmatização da pobreza. Contudo, há dois vetores que podem organizar uma criança: amor e esperança. Não se apreende por ensaio e erro. Se apreende por confiança na palavra do outro. O problema principal da escola não está na colocação de limites, senão na construção de legalidades (Bleichmar, 2008).

Como poderíamos repensar essas formas de subjetividade e as novas formas de enlace? Como conceptualizarmos hoje a noção de família? As configurações atuais fugiram há tempo do perfil de família margarina. Há inúmeras configurações de famílias: monoparentais, de casais homossexuais, avós que cuidam de netos sozinhas...

Bleichmar (2008) propunha chamar de família qualquer configuração na qual convivessem pelo menos duas gerações, com certa estabilidade de suas funções, sendo a mais importante a de proteção e cuidado dos mais débeis para lhes garantir um lugar no mundo e um desenvolvimento que não os deixasse largados à morte física ou simbólica.

Refletindo sobre a violência nas escolas, ela afirmava que as escolas deviam voltar a se ocupar em ensinar e em transmitir valores como amizade, solidariedade. E não somente se tornarem locais de assistência social. E que a violência era resultado do ressentimento pelas promessas não cumpridas e pela falta de perspectiva de futuro. Há muito pouco espaço nas escolas das periferias brasileiras para a esperança, para reconstruir legalidades. A construção de esperança passa por uma dupla torção: um trabalho no presente para acreditar que saberemos construir um futuro.

Tenho procurado aproximar conceitos da clínica Winnicottiana para a fundamentação de políticas públicas para os jovens infratores ou crianças com algum grau de comportamento antissocial (Onocko-Campos, 2012, 2018). Isso deveria nos levar a pensar em que tipo de agentes precisamos como educadores e na falência do que chamarei "função adulto" no Brasil. 
A função adulto implica na assumpção de uma assimetria básica e estruturante da relação entre adultos e crianças/jovens. É essa assimetria, precisamente, a que interdita o goze do adulto sobre o corpo infantil. Parece-me que no contemporâneo (e isso não só nas regiões pauperizadas) há um certo temor dessa assimetria estruturante. Que implica em responsabilizar-se - e não, como geralmente se entende - em, simplesmente, mandar. Como se houvesse um temor de exercer modelos autoritários pela existência dessa assimetria ${ }^{4}$. Contudo, ela diz respeito da responsabilização e não do uso do poder. Espera-se de adultos ao cuidado de crianças que sejam capazes de limitar a agressão; que suportem um certo grau de maldade (panelinhas, fofocas, invejas) e que não deixem o exercício da autoridade às crianças (o que, para Winnicott, 2005, se tornaria fonte de autoritarismo, ditadura).

Porém, muitos adultos que se desempenham como educadores ou nos serviços de saúde e assistência social tem dificuldades para exercer essa função, pois são eles próprios carentes de uma organização psíquica que lhes permita outros espaços de sublimação. Adultos com estrutura narcísica fraca que buscam reparação no amor ou obediência dos jovens. Adultos com medo da própria agressividade recalcada que gostariam de trabalhar com um bando de ovelhinhas: não permitem experimentar nem a agressividade, nem a inveja. Mais assustador ainda (mas, lamentavelmente muito comum nas instituições de custódia) adultos sádicos. $\mathrm{O}$ mito da criança "anjinho" cria monstros. Winnicott dizia: "só se soubermos que a criança quer derrubar a torre de cubos, será importante para ela vermos que sabe construí-la" (DWW, 2005 p. 101)

Os baixos salários do setor público contribuem para esse quadro desolador, pois sendo sentido o pagamento como insuficiente - no simbólico - alguém terá de pagar o que falta, e serão as crianças, os pacientes demandados a pagar com obediência ou amor. Isso impede o exercício da função adulto, seja na clínica, seja na educação. Ora, a função adulto é civilizatória.

\footnotetext{
${ }^{4}$ Quem sabe uma herança de nosso passado autoritário.
} 
Poderia me estender em exemplos: pais que não conseguem dizer não aos seus filhos adolescentes, pais que deixam "escolher" horários a crianças da pré-escola, pais que entopem seus filhos de gadgets, mas não conversam. Educadores que consideram "incontrolável" crianças de 3 anos de idade.

\section{- O racismo}

O racismo é, talvez, uma das formas de violência mais recalcada no Brasil. Até muito recentemente, a maioria dos professionais de saúde dos serviços públicos era branca (pois eram brancos quem mais acessava as universidades). Como compartilhar com um psicólogo branco que se sofreu preconceito e maus tratos pelo simples fato de ser mulher e negra?

Só muito recentemente fomos alertados sobre isso, assim que as novas gerações de profissionais negros foram ocupar os postos de trabalho nas comunidades. Inúmeras respostas inéditas surpreenderam nossas práticas: jovens em tratamento em CAPS AD perguntando para psicólogos negros se eles também poderiam fazer universidade (numa clara movimentação identificatória e criadora de esperança); jovens profissionais negros questionando em um serviço de saúde mental os comentários racistas de uma usuária esquizofrênica (doença não pode ser álibi para crime); crianças realizando oficina de beleza negra e turbantes após experimentar uma cena racista em um centro de convivência...

Nós, psicanalistas tendemos a pensar a organização do psiquismo de maneira universal. Contudo, desejaria destacar que há sim uma marca violenta na história da subjetivação de muitas pessoas negras, em sua história familiar, em seu dia-a-dia escolar ou de trabalho e que acolher essa violência, reconhecer seu estatuto de realidade é profundamente terapêutico para essas pessoas e famílias.

Trata-se de um posicionamento ético, porém radicalmente clínico. Permitir que algo da ordem do traumático e transgeracional possa ser elaborado e não simplesmente passado à frente sem mudança, reforçando um ciclo de repetições violentas. Precisamos trazer uma adequada valorização do ambiente e dos efeitos da transmissão transgeracional (Corrêa, 2000) às nossas abordagens clínicas. 


\section{- A violência}

"Hay que terminar con el mito de que la violencia es fruto de la pobreza"

Bleichmar (2008) propunha inverter a discussão sobre seguridade (mais vigilância, mais polícia) enfatizando, em vez disso, a temática da impunidade. A impunidade seria aquilo que, se infiltrando no tecido social, teria acabado com a cultura do trabalho e da ética. Hello Brasil?

Não se trata de "incluir" os setores empobrecidos na vida social, senão de produzir uma reinclusão. Ou seja, produzir processos de reciudadanização dessas pessoas. Como psicanalistas podemos contribuir para que a sociedade como um todo possa reabsorver os restos do despedaçamento social que vivemos. Há ali em jogo algo da ordem do traumático, que não pode ser simbolizado e/ou representado. Quando os serviços de saúde se burocratizam ou se omitem, esse silencio, essa não resposta tornam-se mais uma forma de crueldade, de violência silenciosa que retroalimenta o circuito violento.

Há um imenso sofrimento silencioso que precisa ser falado, não para ficar sentados no queixume, senão para ativar a produção de laços horizontais, de compartilhamento e de solidariedade. Tudo o que implique formações comunitárias é subjetivante hoje. Tudo o que implique nexos de solidariedade e de trabalho compartilhado. De amizade. A amizade é revolucionária! Podemos e devemos ajudar a criar dispositivos de compartilhamento.

Os seres humanos precisamos sentir que o que fazemos tem algum sentido, além da mera sobrevivência. Como psicanalistas podemos contribuir para a recriação de um tecido social nesta conjuntura tão esgarçada. Nos comprometendo com a criação e o cuidado de instancias nas quais possam se pensar os modos de relação com o próximo; as formas de resolução do traumático, e as relações entre o simbólico e a vida. 


\section{Referências}

Bleichmar, S. 2008. Violencia social, violencia escolar: de la puesta de limites a la construcción de legalidades. Buenos Aires: Ediciones Novedades Educativas.

Corrêa, OBR. Os avatares da transmissão psíquica geracional. São Paulo: Editora Escuta.

Onocko-Campos RT et al. Salud Colectiva y Psicoanálisis: entrecruzando conceptos en busca de políticas públicas potentes. In: Salud Colectiva, Buenos Aires, 4(2):173-185, Mayo Agosto, 2008

Onocko-Campos RT. Psicanálise e saúde coletiva. São Paulo: Hucitec; 2012

Onocko-Campos RT, 2018. Comportamento antissocial nos jovens como sequela da privação: contribuições da clínica winnicottiana para as políticas públicas. In: Interfaces 2018, DOI: 10.1590/1807-57622017.0315

Soares, JSF \& Lopes, MJM. Experiências de mulheres em situação de violência em busca de atenção no setor saúde e na rede intersetorial. In: Interfaces 2018, DOI: 10.1590/180757622016.0835

Winnicott DW. Privação e delinquência. 4a ed. São Paulo: Martins Fontes; 2005. 